\title{
Efficacy of Miniature Punch Grafting Followed by Puvasol Therapy in Refractory Stable Vitiligo
}

\author{
Gupta A ${ }^{1}$, Chaudhary $C^{2}$, Goyal V ${ }^{3}$, Lal D ${ }^{4}$, Gupta SK ${ }^{5}$ \\ ${ }^{1}$ Assistant Professor, ${ }^{3}$ Profesor, Department of Dermatology, AIMSR, Bathinda, Punjab, ${ }^{2}$ Assistant Professor, ${ }^{4}$ P.G. $2^{\text {nd }}$ \\ year, Dept of Community Medicine, AIMSR, Bathinda, Punjab, ${ }^{5}$ Professor \& Head, Department of Dermatology, DMC, \\ Ludhiana.
}

\author{
Address for correspondence \\ Dr. Anu Gupta \\ Department of Dermatology, AIMSR \\ Bathinda, Punjab, India \\ Mob: 9872401332 \\ E-mail: anu2734@gmail.com
}

\begin{abstract}
Introduction: Vitiligo affects approximately $2 \%$ of the worldwide population regardless of race, ethnic background or gender. When the medical methods are not successful, surgical procedures may be considered with the aim of placing a new source of pigment cells to reinitiate melanogenesis within the affected areas. This study was conducted to evaluate the efficacy of combining punch grafting followed by PUVASOL therapy in vitiligo patients. After punch grafting patients are given PUVA/PUVASOL exposure.

Objective: To study the efficacy of miniature punch grafting followed by PUVASOL therapy in refractory stable vitiligo.

Material and Methods: The present study was conducted in the Department of Dermatology and Venereology of Dayanand Medical College \& Hospital, Ludhiana from May 2005 to March 2007. Fifteen patients of chronic stable vitiligo not responding to medical treatment and attending the outpatient department of dermatology were included in study. Appropriate statistical methods were used to analyse the data.

Conclusion: Patients subjected to Miniature Punch Grafting showed more than $80 \%$ acceptance in all selected age groups and among both the sex. There was an inverse relationship between number of grafts inserted and rejection rate. Most common side effect seen was cobblestoning (60\%) with few patients showing graft displacement and hematoma formation too.
\end{abstract}

Key words: vitiligo, miniature punch grafting, puvasol

\section{Introduction}

$\mathrm{V}$ itiligo affects approximately $2 \%$ of the worldwide population regardless of race, ethnic background or gender. About $10 \%$ of cases are localized and $90 \%$ are generalized. There are a number of medical therapies that may restore, improve or at least decrease the depigmentation. These are topical corticosteroids, calcipotriol, topical or systemic methoxypsoralen, and oral psoralen plus ultraviolet $A$ radiation (PUVA), ultraviolet $B$ (UVB) radiation, pseudocatalase plus calcium plus UVB, vitamin supplementation, human placental extract, systemic corticosteroids, other immunomodulators, and topical L-Phenylalanine in combination with UVA (PAUVA) ${ }^{1,2}$. However, such treatments usually induce incomplete repigmentation and occasionally the outcome is poor ${ }^{2-4}$.
When the medical methods are not successful, surgical procedures may be considered with the aim of placing a new source of pigment cells to reinitiate melanogenesis within the affected areas. Several surgical procedures for the treatment of intractable lesions have been reported to be effective, including thin Thiersch grafts, suction-blistered epidermis ${ }^{1,3}$, minigrafting ${ }^{4,5}$ and injection of non-cultured and various cultured cell grafting techniques. Only patients in whom the vitiligo is stable (i.e. no progression within 4 to 6 months) are considered good candidates for grafting.

On the other hand PUVA, either systemic or topical, increases the number of melanocytes and synthesis of melanin ${ }^{2}$. Topical outdoor PUVA is a popular and efficacious therapeutic option for patients with 
limited vitiligo ${ }^{6}$. The mechanism of PUVA rests on the synergistic interaction of the two components (8methoxypsoralen and UVA light) in the skin?

This study was conducted to evaluate the efficacy of combining punch grafting followed by PUVASOL therapy in vitiligo patients. This procedure is adapted only when the disease is stable for a sufficient period of time. In punch grafting small (1-2 $\mathrm{mm}$ ) round, full thickness grafts are harvested with a trephine from a pigmented site and transplanted into an area of vitiligo. It causes restoration of melanocytes in the depigmented skin. Such repigmented skin then regains its normal immune / inflammatory function ${ }^{8}$.

After punch grafting patients are given PUVA/ PUVASOL exposure. It stimulates tyrosinase activity in melanocytes and may stimulate other components of skin, such as keratinocytes to release inflammatory mediators. Some of those may act as basic fibroblast growth factor (bFGF) and may enhance further proliferation of melanocytes. Giving PUVASOL therapy after punch grafting helps in perifollicular repigmentation. It has been found that during adequate systemic methoxypsoralen therapy, melanocytes are stimulated, migrate from the hair follicle reservoir, and spread centrifugally from the infundibulum into the basal cell layer, recolonizing the epidermis with functional pigmentary cells $s^{9,10}$.

\section{Objective}

To study the efficacy of miniature punch grafting followed by PUVASOL therapy in refractory stable vitiligo.

\section{Material \& Methods}

The present study was conducted in the Department of Dermatology and Venereology of Dayanand Medical College \& Hospital, Ludhiana from May 2005 to March 2007. Fifteen patients of chronic stable vitiligo not responding to medical treatment and attending the outpatient department of dermatology were included in the study. In stable vitiligo there were no new lesions and no progression seen in the previous lesions for the past one year. After doing punch grafting PUVASOL therapy was given and patients were followed for a period of 12 weeks i.e. 3 months.

Patients with unstable vitiligo, children $<12$ years of age, pregnant and lactating women, patients with history of intolerance to PUVA/PUVASOL, patients with past history or family history of skin cancers, patients with renal disease / liver disease, patients having any chronic debilitating diseases and tendency to develop hypertrophic scars or keloids were excluded from the study.

Preliminary investigations which were carried out are :- 1 . Complete blood counts 2. Urine routine 3. Liver function tests 4 . Renal function tests 5 . Ophthalmoscopic examination.

Informed consent of the patient was taken before miniature punch grafting. Both donor and recipient areas were prepared aseptically by cleaning them thoroughly with savlon, followed by betadine and spirit. At the recipient area $2.5 \mathrm{~mm}$ punches were taken out at a distance of 5-10 mm. The punched out tissue was discarded. Donor area was buttock or front of thigh. From donor area $3 \mathrm{~mm}$ punches were taken and kept in a petridish containing normal saline. The donor area was dressed with antiseptic dressing. The $3 \mathrm{~mm}$ punches from the donor site were placed in $2.5 \mathrm{~mm}$ crators created at the recipient site. The edges were ironed out and grafted area was covered with nonsticking framycetin dressing and then pressure dressing was given using dynaplast. The patients were also advised a course of antibiotic therapy and analgesics for a week and allowed to go home immediately after dressing with the instructions to avoid any vigorous activity which could displace the dressing. Patients were then called after $48 \mathrm{hrs}$ to change the dressing and further follow up was after one week when patients were examined and complications if any were noted.

After 15 days of punch grafting, patients were given PUVASOL therapy, where we gave tab 8-methoxypsoralen in the dosage of $0.6 \mathrm{mg} / \mathrm{kg} / \mathrm{day}$ twice a week and then the patients were asked to expose the affected area to natural sunlight after 2 hours. While on PUVASOL patients were instructed to protect their eyes from direct sunlight with the help of UV opaque goggles on the day of PUVASOL. Initially sun exposure was for 5 minutes and 5 minute increment was given after every three sittings, subject to a maximum of 30 minutes. Patients were followed at 2 weekly intervals for total of 12 weeks. On every follow up visit, the grafted area was examined for evidence of new pigment development (i.e. repigmentation). Close up clinical photographs were taken. The results obtained were recorded in performa.

In the end of the study, the results obtained were compiled and subjected to appropriate statistical procedure to arrive at valid conclusions. 


\section{Result}

Fifteen patients of chronic stable vitiligo who were not having any problem mentioned in the exclusion criteria and reported in the study period were taken for the study. The mean age group of the study population was 23.93 years. Majority of them were females and from urban areas (Table 1). Most of the patients had surface area involvement in the range of $0.3-0.5 \%$ with a mean of 0.49 of total body surface area. The duration of the disease varied from 1 to 16 years. Majority of the patients (53.33\%) had disease duration ' $6-10$ years. Most of the patients had segmental form of the disease $(67 \%)$ with (13\%) having generalized and (20\%) focal form of the disease (Table 2).

The number of grafts inserted per patient varied from 12 to 62 (Table 3). Percentage acceptance in different age groups varied from 81.36 to $87.26 \%$. The difference in the graft acceptance rate in different age groups was not statistically significant (Table 4). Percentage acceptance in males was 92.10 while in females was 83.53. However the difference in graft acceptance between males and females was not statistically significant. The mean of grafts accepted was 30.67 with SD of 13.66 and mean of grafts rejected was 5.00 with SD of 2.36 (Table 5).

Most common side effect observed was cobblestoning which was observed in $60 \%$ of the patients. Other side effects which were observed were hematoma formation and displacement of the graft (Table 7). Mean pigmentation attained after 4 weeks of PUVASOL was $78.67 \%$, which progressively increased and maximum repigmentation was seen at 12 weeks i.e. $90.13 \%$. So there was significant repigmentation after 12 weeks after PUVASOL. Most common side

Table 1: Sociodemographic characteristics of the study group

\begin{tabular}{|c|c|c|}
\hline & No of Patients & Age (\%) \\
\hline \multicolumn{3}{|l|}{ Age Group } \\
\hline $11-20$ & 5 & 33.33 \\
\hline $21-30$ & 8 & 53.33 \\
\hline $31-40$ & 0 & 0 \\
\hline $41-50$ & 2 & 13.33 \\
\hline Mean & 23.93 & \\
\hline \multicolumn{3}{|l|}{ Sex } \\
\hline Male & 5 & 33.33 \\
\hline Female & 10 & 66.67 \\
\hline \multicolumn{3}{|c|}{ Area of Residence } \\
\hline Rural & 4 & $26.7 \% \%$ \\
\hline Urban & 11 & $73.3 \%$ \\
\hline
\end{tabular}

effect with PUVASOL was erythema seen in $40 \%$ of the patients while itching was seen in $20 \% .40 \%$ didn't experience any side effect of PUVASOL. However none of the patients discontinued treatment due to side effects of PUVASOL (Table 8).

Table 2: Description of the vitiligo

\begin{tabular}{|c|c|c|}
\hline $\begin{array}{l}\text { Body Surface Area } \\
\text { (Bsa) Involved ( \%) }\end{array}$ & No. & Percentage (\%) \\
\hline 0.1 & 2 & 13.3 \\
\hline $0.1-0.3$ & 3 & 20 \\
\hline $0.3-0.5$ & 6 & 40 \\
\hline $0.5-0.7$ & 0 & 0 \\
\hline $0.7-1$ & 4 & 26.7 \\
\hline Mean & 0.49 & \\
\hline $\mathrm{Sd}$ & 0.34 & \\
\hline \multicolumn{3}{|c|}{ Duration of Vitiligo ( Yrs) } \\
\hline $1-5$ & 5 & 33.33 \\
\hline $6-10$ & 8 & 53.33 \\
\hline $11-16$ & 2 & 13.33 \\
\hline \multicolumn{3}{|l|}{ Type of Vitiligo } \\
\hline Generalized & 2 & 13 \\
\hline Focal & 3 & 20 \\
\hline Segmental & 10 & 67 \\
\hline
\end{tabular}

Table 3: Age wise distibution of Graft inserted

\begin{tabular}{|c|c|c|}
\hline Age (Yrs) & $\begin{array}{c}\text { No. Of Patients With } \\
\text { Graft Inserted }\end{array}$ & $\begin{array}{c}\text { Percentage } \\
\text { (\%) }\end{array}$ \\
\hline $11-20$ & 4 & 26.67 \\
\hline $21-30$ & 1 & 6.67 \\
\hline $31-40$ & 4 & 26.67 \\
\hline $41-50$ & 4 & 26.67 \\
\hline$>50$ & 2 & 33.33 \\
\hline Total & 15 & \\
\hline
\end{tabular}

Table 4: Grafts acceptance in relation to sex

\begin{tabular}{|c|c|}
\hline Sex & \\
\hline Male & 92.10 \\
\hline Female & 93.53 \\
\hline P Value & $>0.01$ \\
\hline
\end{tabular}

Table 5 : Distribution of subjects according to no. Of grafts rejected:

\begin{tabular}{|c|c|c|}
\hline Graft Rejected & No of Patients & Percentage \\
\hline $2-3$ & 4 & 26.67 \\
\hline $4-5$ & 6 & 40 \\
\hline $6-7$ & 2 & 13.33 \\
\hline $8-10$ & 3 & 20 \\
\hline Mean & 5 & \\
\hline SD & 2.36 & \\
\hline
\end{tabular}


Gupta A et al.

Table 6: Grafts inserted, rejected and percent rejection

\begin{tabular}{|c|c|c|c|c|c|}
\hline \multicolumn{3}{|c|}{ No. of Grafts Inserted } & \multicolumn{2}{c|}{ No. of Grafts Rejected } & Percentage of Rejection \\
\hline No. & Mean & SD & Mean & SD & \\
\hline $11-20$ & 17.5 & 3.79 & 4.00 & 0.82 & 23.75 \\
\hline $21-30$ & 25 & - & 5 & - & 20.00 \\
\hline $31-40$ & 34 & 1.41 & 3.75 & 2.87 & 11.08 \\
\hline $41-50$ & 46.75 & 1.71 & 5.75 & 2.06 & 12.33 \\
\hline$>50$ & 58.5 & 4.95 & 8 & 2.83 & 13.52 \\
\hline
\end{tabular}

Table 7: Side effects

\begin{tabular}{|c|c|c|}
\hline Side Effect & No of Patients & Percentage \\
\hline Displacement of Graft & 5 & 33 \\
\hline Cobble Stonning & 9 & 60 \\
\hline Hematoma & 1 & 7 \\
\hline
\end{tabular}

Table 8: Trends in pigmentation achieved:

\begin{tabular}{|c|c|c|}
\hline Time (Weeks) & Mean (\%) & SD \\
\hline 4 & 28.67 & 10.26 \\
\hline 6 & 47 & 9.6 \\
\hline 8 & 66 & 9.3 \\
\hline 10 & 81.67 & 6.73 \\
\hline 12 & 90.13 & 3.89 \\
\hline
\end{tabular}

F Ratio: 137.72

$p$ value $<0.01$

CD: 6.04

\section{Discussion}

Vitiligo is a common pigmentary disorder leading to great cosmetic embarrassment, psychological distress and a cause of disruption of social relationship. The outcome of this disorder is often unpredictable and uncertain. There are many cases of vitiligo who either fail to respond or only partially respond to the medical line of treatment indicating that melanocyte reservoir is no more available for repigmentation in these areas $^{11}$. These non responding cases of stable vitiligo can be treated with autologous skin grafting. Autologous skin grafting can be done in various ways such as epidermal culture grafting ${ }^{12}$, pure melanocyte culture grafting ${ }^{14}$, epidermal grafting by suction blister technique ${ }^{13}$, thin Thiersch's split skin grafting ${ }^{15}$, or thin split skin miniature punch grafting. The later method was first advocated by Falabella to treat small to medium sized localized patches of focal and segmental vitiligo $0^{4,5}$.

The age range in our study was between $12-50$ years. Majority of the patients were in the age group of 21-30 years with a mean age being 23.9 years. In a study done by Malakar and Dhar ${ }^{22}$, majority of the cases were in the age of $10-30$ years with a mean age of 20 years. So age group included in our study was almost similar to other studies. Vitiligo affects both sexes equally. However many studies have shown female preponderance of vitiligo $^{16,17}$. In present study also majority i.e. $66 \%$ of patients were females. In fact, this may be a reflection that females are more concerned about cosmetic looks and are more stressed due to social and matrimonial problems due to the disease. Most of the patients in our study (73.35\%) were residents of urban area and large majorities (86.7\%) were educated. This could be due to the fact that urban educated patients are more concerned regarding the cosmetic disfigurement resulting from vitiligo.

Most of our patients had segmental vitiligo (67\%), followed by focal vitiligo (20\%) and generalized vitiligo $(13 \%)$. This is in concordance to other studies ${ }^{7,18}$ that also included cases with focal and segmental vitiligo. The duration of vitiligo ranged from 1-16 years with a mean of 7.17 years (53.33\%). 8 patients had disease duration between $6-10$ years, 5 patients (33.33\%) between 1-5 years and rest 2 patients disease duration between 1-16 years. Also the surface area involvement was in our study in range of $0.3-0.5 \%$ of total body surface area with a mean of 0.49 . 
The number of grafts inserted per person in the study varied between 12-62 with a mean of 35.67 grafts and in majority of patients 30-50 grafts were put. Mean percentage of acceptance of graft was $84.29 \%$. There was no statistically significant difference in the graft acceptance rate in two sexes and in different age groups. Percentage graft rejection was $15.71 \%$ and it was found that as the number of grafts inserted increased, rejection percentage decreased. Percentage of graft rejection in another study conducted by Rathi ${ }^{19}$ due to various reasons like movement, secondary infection was around $10 \%$.

The most important side effect observed was cobblestoning seen in $60 \%$ of the patients while displacement of graft with hematoma formation (33\%) and hematoma formation alone was seen in (7\%) of the patients. This is in concordance with the study done by Savant ${ }^{20}$ who also observed cobblestoning as the commonest side effect seen in $50 \%$ of the patients. In a study done by Bajaj ${ }^{18}$, cobblestoning was observed in $22 \%$. It was seen in 10 patients (total 32 cases) in the initial stages but with the passage of time it was rectified in majority of the patients. Rathi et $\mathrm{al}^{19}$ also observed cobblestoning in $22.5 \%$ with sinking pits in $10 \%$. No case of sinking pits was observed in the present study. This could be due to relatively small study group. The displacement of graft(s) observed in the study was due to improper immobilization by the patients. Savant ${ }^{20}$ observed three cases of contact allergic dermatitis to framycetin but no case showed framycetin allergy in present study.

Postoperative PUVASOL was given and the commonest side effect observed was erythema (40\%), itching (20\%) and another $40 \%$ didn't experience any side effect due to PUVASOL. None of the patients however required discontinuation of therapy due to side effects. Trends in repigmentation were observed for up to 12 weeks. Mean repigmentation attained after 4 weeks of PUVASOL was $28.67 \%$ which progressively increased and maximum repigmentation was seen at 12 weeks (90.13\%). There was significant improvement in the repigmentation achieved with the passage of time and

\section{References}

1. Boersrna BR, Westerhof W, Bos JD. Repigmentation in Vitiligo vulgeris by autologous minigrafting: Results in nineteen patients. J Am Acad Dermatol 1995; 33: 990-5. https://doi.org/10.1016/0190-9622(95)902929 postoperative PUVASOL therapy has been found to expediate repigmentation. In another study, Falabella ${ }^{5}$ developed his own technique using minipunch to treat localized vitiligo. Total 15 patients received treatment by mini grafting and remarkable repigmentation was obtained in 13 cases with $90-100 \%$ improvement, in one case $70 \%$ and another one $50 \%$ improvement. However no sealing solution was used in this study to secure the grafts as in Falabella's technique since simple pressure was enough to secure them. In a prospective study of 1000 patients of stable and recalcitrant vitiligo the results of miniature punch grafting was evaluated by Malakar and Dhar ${ }^{23}$. In 656 (74.55\%) patients, 90$100 \%$ repigmentation was achieved, in 93 (10.57\%) patients there was no spread of pigment, while in 21 (2.39\%) depigmentation of the graft was noticed. In another study 33 patients were selected by Jha et al ${ }^{21}$ for punch grafting. They modified the method which was described by Falabella and Behl by using one punch per $\mathrm{cm}^{2}$ using $3 \mathrm{~mm}$ punch device. There was complete repigmentation in 10 patients and in 23 patients pigmentation was spreading slowly. No recurrence or scar was noticed at donor or recipient site in any of the patients. Rate of repigmentation observed in the present study is similar to other study.

\section{Conclusion}

The study on patients of vitiligo who were subjected to Miniature Punch Grafting showed more than $80 \%$ acceptance in all selected age groups and among both the sex. There was an inverse relationship between number of grafts inserted and rejection rate. Most common side effect seen was cobblestoning (60\%) with few patients showing graft displacement and hematoma formation too. Mean pigmentation achieved after 12 weeks of PUVASOL was above $90 \%$ and there were some adverse effects with PUVASOL however none of the patients discontinued the treatment due to the side effects. Mini punch grafting with PUVASOL is very effective for attaining excellent re-pigmentation. Post-operative PUVASOL therapy has been found to expediate this re-pigmentation.

2. Grimes PE. Therapies for vitiligo In: Millikan LE., ed. Drug Therapy in Dermatology. $1^{\text {st }}$ ed. New York: Marcel Dekker 2000; 339-57

3. Falabella R. Surgical techniques for repigmentation. In Robinson JK, Arndt KA, Loboit PE, ed S. Altas of cutaneous surgery, $1^{\text {st }}$ ed, Philadelphia: WB Saunders, 1996; 175-84. 
4. Falabella R. Repigmentation of segmental vitiligo by autologous minigrafting. J Am Acad Dermatol 1983; 9: 514-21. https://doi. org/10.1016/S0190-9622(83)70162-3

5. Falabella R. Treatment of localized vitiligo by autologous minigrafting, Arch Dermatol 1988; 124: 1649-55. https://doi.org/10.1001/ archderm.1988.01670110009002

6. Grimes PE. Therapeutic trends for the treatment of vitiligo. J Cosm Dermatol 2002; 6:21-5

7. Shephard SE, Langguth $P$, Panizzon RG. Pharmacokinetic behaviour of sublingually administered 8-methoxypsoralen for PUVA therapy. Photodermatol Phtoimmunod photomed 2001; 17: 11-21. https://doi. org/10.1034/j.1600-0781.2001.017001011.x

8. Drake LA, Dinehart SM, Farmer ER, Goltz RW, Graham GF, Hordinsky MK et al: Guidelines of care for vitiligo. J Am Acad of Dermatol 1996; 35(4): 620-6

9. OrtonneJP, Mac Donald DM, Micound A, Thiovelt J. PUVA induced repigmentation of vitiligo: $A$ histochemical (split-dopa) and ultrastructural study. Br J Dermatol 1979; 101: 1-12. https:// doi.org/10.1111/j.1365-2133.1979.tb15285.x

10. Ortonne JP, Schimitt D, Thiovelt J. PUVA induced repigmentation of vitiligo: scanning electron microscopy of hair follicles. J Invest Dermatol 1980; 74:40-2. https://doi.org/10.1111/15231747.ep12514597

11. Das SS, Pasricha JS. Punch grafting as treatment of residual lesions of vitiligo. Ind J Dermatol Venereol and Leprol 1992;40:172-7.

12. Brysk MM, Newton RC, Rajaram S, Plott T, Barlow E, Bell T et al. Autologous culture cells as treatment for vitiligo. J Invest Dermatol 1988;90:549.

13. Koga M. Epidermal grafting using tops of suction blisters in treatment of Vitilogo. Arch dermatol 1988; 124: 1656-8. https://doi.org/10.1001/ archderm. 124.11.1656
14. Lerner AB, Halaban R, Klauss SN, Moellmann GE et al. Transplantation of human melanocytes. J Invest Dermatol 1987; 89: 219-24. https://doi. org/10.1111/1523-1747.ep12470973

15. Behl PN, Bathia RK. Treatment of Vitiligo with homologous thin Theirsch's grafts. Int J Dermatol 1973; 12: 329-33. https://doi. org/10.1111/j.1365-4362.1973.tb00068.x

16. Mosher DB, Fitzpatrick TB, Ortonne JP. Hypomelanosis and Hypermelanosis. In Wolff K, Austen KF, Goldsmith LA, Fitzpatrick TB eds. Dermatology in general medicine, $6^{\text {th }}$ edn. New York: Mc Graw Hill 2003: 836-81.

17. Dutta AK, Dutta PK. Pigmentory disorders. In : Valia RG, Valia AR eds. IADVL. Textbook of Dermatology, Bhalani Publisshing House,I Bombay 1994: 500-86.

18. Singh KG, Bajaj AK. Autologous miniature skin punch grafting $n$ vitiligo. $2^{\text {nd }} \mathrm{J}$ Dermatol Venerol Leprol 1995; 61: 77-80.

19. Rathi MK, Singh AK. Punch grafting in the treatment of stable vitiligo. $2^{\text {nd }} \mathrm{J}$ Dermatol Venerol and Leprol 1994; 60: 188-92.

20. Savant SS. Autologous miniature punch skin grafting in stable vitiligo. Ind J Dermatol Venerol Leprol 1992; 58: 310-4.

21. Jha AK, Pandey SS, Shukla VK. Punch grafting in vitiligo. $2^{\text {nd }}$ Dermatol Venerol and Leprol 1992; 58: 328-30.

22. Riley PA. Mechanism of pigment cell toxicity produced by hydroxyanisole. J Pathol 1970; 101: 163-9. https://doi.org/10.1002/ path. 1711010211

23. Malakar S, Dhar S. Treatment of stable and recalcitrant vitiligo by autologous miniature punch grafting : a prospective study of 1000 patients. Dermatology 1999; 198: 133-9. https://doi.org/10.1159/000018089 